\title{
Limiting our daily sitting/lying to just 23.5 hours: too ambitious?
}

\section{Karim Khan}

Thank you to BJSM guest editor Steven Blair ${ }^{1}$ and all our January and February authors (http://bjsm.bmj.com/content/ vol43/issue1; http://bjsm.bmj.com/content/ vol43/issue2). If we apply Bono's battle cry "There has been a lot of talk, maybe too much talk"...to the subject of physical inactivity, we can now proclaim it's time for action. The January and February $B J S M$ issues bring together global authorities and focus on practical steps. Medical clinicians will be interested in the analysis by Erica Frank and colleagues (see page 124) of the activity levels of medical students and their propensity to prescribe physical activity (or not!). ${ }^{2}$ Is it time to add a physical activity question to the medical student selection process? Should the Medical College Admission Test ask for a shuttle run/beep test score?

\section{EXERCISE PHYSIOLOGISTS, PHYSIOTHERAPISTS AND FAMILY PHYSICIANS: DOING YOUR PART?}

Barry Franklin and colleagues ${ }^{3}$ make a compelling case for the role of the exercise physiologist in clinical exercise prescription; the clinical exercise physiologist will be a new concept to some readers. Evert Verhagen bats for physical therapists/physiotherapists ${ }^{4}$ and Nefyn Williams shares his wisdom as to how family physicians can instill in patients that "the wise, for cure, on exercise depend". 5

\section{AN OVERLOOKED RISK FACTOR IN THE "SPORTS MEDICINE WORLD": THE PHYSICAL ENVIRONMENT}

The link between the physical environment and inactivity has been largely ignored in the sports medicine literature. Anyone who has tried to "walk" the halfmile (crow flies) between a conference hotel and an American College of Sports Medicine convention centre by climbing

Correspondence to: Professor K M Khan, Centre for Hip Health and Mobility and Department of Family Practice, University of British Columbia, Vancouver, Canada; karim.khan@familymed.ubc.ca up the freeway embankment, stepping over the steel barriers, dashing hopefully across breaks in eight lanes of Hummers and then navigating a clover-leaf interchange using the global positioning system in the iPhone, knows that the environment has something to do with activity levels. Those of you who took the 4-mile trip by limo to the same destination were probably already convinced. Billie Giles-Corti and Abby King bring a two-nation perspective to the environment's role across the lifespan. ${ }^{6}$ Inconvenient truths for city planners. Larry Frank and colleagues, ${ }^{7}$ including Jim Sallis, report rare original data on the role of food outlet visits in a study of $>10000$ participants. BJSM is delighted to start to bring these important determinants of health to readers' attention.

\section{MORE INNOVATIONS IN THIS PRACTICAL ISSUE: USING COMPUTER-BASED INTERVENTIONS}

Now here's a case of poacher turned gamekeeper! Or is a "jiu-jitsu move" a better analogy? Why not use the scourge of physical inactivity - computers - to promote activity! Bess Marcus, who put Rhode Island back on the world map after Newport lost its claim to the America's Cup competition, shares evidence and makes practical suggestions. ${ }^{8}$ Ready to use. No down time.

\section{AND THE COVER STORY: DON'T TAKE IT SITTING DOWN!}

As the late night knife advertisements say: "all this and much, much more!" Physical activity is a legitimate medical therapy; when will we treat it as the magic bullet and polypill it is? ? $^{9}$ Avoiding inactivity is also crucial! Sedentary behaviour itself is an independent risk factor for chronic disease. Epidemiologists Owen, Brown and Bauman ${ }^{10}$ provide the steak for $B M J$ cartoonist Malcolm Willett's "sizzle": the cover of this issue. The same authors also review how this field has developed over 50 years. Editorial Board member George Santayana suggested we accept that paper because "those who cannot remember the past are condemned to repeat it".

So speaking of history (http://www youtube.com/watch?v = Eih_ybKdVXU), don't forget to check back to the January issue for the supersized version of BJSM Physical Activity. Also, you probably missed the December issue when you were busy baking, and wrapping gifts. December's BJSM focused on back pain and included Paul Hodges' rare summation of a decade that traverses 130 studies. ${ }^{11}$ Those three concise pages are compulsory reading - even if you have to sit for a few moments to do it.

Also, please do check out the BJSM blog (http://blogs.bmj.com/BJSM), keep an eye (ear?) out for our monthly podcasts. They'll be signalled on the home page. But in the meantime, let's all try to limit our lying down and sedentary behaviour to just 23.5 hours per day. Perhaps even to 23 hours a day for the real zealots! Or is that just too high a price for years of improved quality of life?

Competing interests: None.

Br J Sports Med 2009;43:79.

doi:10.1136/bjsm.2009.057349

\section{REFERENCES}

1. Blair SN. Physical inactivity: the biggest public health problem of the 21st century. Br J Sports Med 2009; 43:1-2

2. Lobelo F, Duperly J, Frank E. Physical activity habits of doctors and medical students influence their counselling practices. Br J Sports Med 2009;43:89-92.

3. Franklin B, Fern A, Fowler A, et al. Exercise physiologist's role in clinical practice. Br J Sports Med 2009;43:93-8.

4. Verhagen $\mathbf{E}$, Engbers L. The physical therapist's role in physical activity promotion. Br J Sports Med 2009;43:99-101.

5. Williams NH. "The wise, for cure, on exercise depend": physical activity interventions in primary care in Wales. Br J Sports Med 2009;43:106-8.

6. Giles-Corti $\mathbf{B}$, King AC. Creating active environments across the life course: "thinking outside the square". Br J Sports Med 2009;43:109-13.

7. Frank L, Kerr J, Saelens B, et al. Food outlet visits, physical activity and body weight: variations by gender and race-ethnicity. Br J Sports Med 2009;43:124-31.

8. Marcus BH, Ciccolo JT, Sciamanna CN. Using electronic/computer interventions to promote physical activity. Br J Sports Med 2009;43:102-5.

9. Church TS, Blair SN. When will we treat physical activity as a legitimate medical therapy... even though it does not come in a pill? Br J Sports Med 2009;43:80-1.

10. Owen N, Bauman A, Brown W. Too much sitting: a novel and important predictor of chronic disease risk? Br J Sports Med 2009;43:81-3.

11. Hodges $\mathbf{P}$. Transversus abdominis: A different view of the elephant. Br J Sports Med 2008;42:941-4. 